\title{
Azathioprine metabolite measurements are not useful for following treatment of autoimmune hepatitis in Alaska Native and other non-Caucasian people
}

\author{
Elizabeth D Ferucci MD MPH${ }^{1}$, Kathy J Hurlburt MD ${ }^{1}$, Marlyn J Mayo MD², Stephen Livingston MD ${ }^{1}$, \\ Heike Deubner MD $^{3}$, James Gove RN¹, Julia Plotnik RN¹, Brian J McMahon MD ${ }^{1}$
}

\begin{abstract}
ED Ferucci, KJ Hurlburt, MJ Mayo, et al. Azathioprine metabolite measurements are not useful for following treatment of autoimmune hepatitis in Alaska Native and other non-Caucasian people. Can J Gastroenterol 2011;25(1):21-27.
\end{abstract}

BACKGROUND: In autoimmune hepatitis (AIH) patients treated with azathioprine, the utility of measuring thiopurine methyltransferase (TPMT) and azathioprine metabolites has been limited.

OBJECTIVE: To evaluate the association between TPMT genotype and enzyme activity, and the impact of TPMT enzyme activity on levels of azathioprine metabolites and leukopenia to assess the clinical utility of monitoring azathioprine metabolites in Alaska Native and other nonCaucasian AIH patients.

METHODS: Individuals with AIH were recruited at the Alaska Native Medical Center (Alaska, USA) and the University of Texas Southwestern Medical Center (Texas, USA). Identification of TPMT genotype and measurement of enzyme activity were performed. The metabolites 6-thioguanine nucleotides (6-TGN) and 6-methylmercaptopurine (6-MMP) were measured in participants who were on azathioprine, and the associations with disease remission and leukopenia were assessed.

RESULTS: Seventy-one patients with AIH were included. The distribution of TPMT genotypes was similar to that reported in other populationbased studies. TPMT genotype and phenotype were strongly associated $(\mathrm{P}<0.0001)$. Levels of 6-TGN and 6-MMP correlated with azathioprine dose only in individuals with normal TPMT enzyme activity. Patients with leukopenia due to azathioprine were no more likely to have abnormal TPMT enzyme levels than those without leukopenia $(\mathrm{P}=1.0)$. No specific level of 6-TGN metabolites was associated with remission or leukopenia.

DISCUSSION: Results of the present study were consistent with previous studies in Caucasian populations. TPMT genotype and phenotype correlated well, and levels of 6-TGN and 6-MMP metabolites were not associated with remission of $\mathrm{AIH}$ or toxicity of azathioprine. CONCLUSIONS: The present study confirmed the limited utility of monitoring levels of azathioprine metabolites in AIH patients.

Key Words: Autoimmune liver disease; Azathioprine; Minority populations; Thiopurine methyltransferase
Les mesures des métabolites de l'azathioprine ne sont pas utiles comme traitement de l'hépatite auto-immune chez des populations d'autochtones de l'Alaska et d'autres populations non blanches

HISTORIQUE : Chez les patients atteints d'une hépatite auto-immune (HAI) traités à l'azathioprine, l'utilité de mesurer la thiopurine méthyltransférase (TPMT) et les métabolites de l'azathioprine est limitée.

OBJECTIF : Évaluer l'association entre le génotype de TPMT et l'activité des enzymes, de même que les répercussions de l'activité des enzymes de TPMT sur les taux de métabolites de l'azathioprine et de la leucopénie pour déterminer l'utilité de mesurer les métabolites de l'azathioprine chez des autochtones de l'Alaska et d'autres patients non blancs atteints d'une HAI.

MÉTHODOLOGIE : Les personnes atteintes d'une HAI ont été recrutées à l'Alaska Native Medical Center (Alaska, États-Unis) et au University of Texas Southwestern Medical Center (Texas, États-Unis). Les chercheurs ont procédé au dépistage du génotype de TPMT et à la mesure d'activité des enzymes. Ils ont mesuré les métabolites de 6-thioguanine nucléotides (6-TGN) et de 6-méthylmercaptopurine (6-MMP) chez les participants qui prenaient de l'azathioprine et ils ont évalué les associations avec la rémission de la maladie et la leucopénie.

RÉSULTATS : Soixante et onze patients atteints d'HAI ont participé à l'étude. La répartition des génotypes de TPMT était similaire à celle déclarée dans d'autres études en population. Le génotype et le phénotype de TPMT étaient fortement associés $(\mathrm{P}<0,0001)$. Les taux de 6 -TGN et de 6-MMP étaient corrélés avec la dose d'azathioprine seulement chez les personnes dont l'activité des enzymes de TPMT était normale. Les patients ayant une leucopénie causée par l'azathioprine n'étaient pas plus susceptibles de présenter des taux d'enzymes de TPMT que ceux ayant une leucopénie $(\mathrm{P}=1,0)$. Il n'y avait pas de taux précis de métabolites de 6-TGN associés à la rémission ou à la leucopénie.

EXPOSÉ : Les résultats de la présente étude corroboraient des études antérieures auprès de populations blanches. Le génotype et le phénotype de TPMT étaient bien corrélés, et les taux de métabolites de 6-TGN et de 6-MMP ne s'associaient pas à la rémission de l'HAI ou à la toxicité de l'azathioprine.

CONCLUSIONS : La présente étude a confirmé l'utilité limitée de surveiller les taux de métabolites de l'azathioprine chez des patients atteints d'une HAI.

alone can be used $(3,4)$. Although azathioprine is associated with a lower risk of side effects than corticosteroids, its toxicity profile in AIH can include bone marrow suppression, nausea, vomiting, rash and pancreatitis $(2,3)$.

Once absorbed, azathioprine is nonenzymatically cleaved into 6-mercaptopurine (6-MP). Further metabolism of 6-MP is catalyzed by two enzymes, hypoxanthine-guanine phosphoribosyltransferase (HPRT) and thiopurine methyltransferase (TPMT). azathioprine and low-dose corticosteroids, or azathioprine

${ }^{1}$ Alaska Native Tribal Health Consortium, Anchorage, Alaska; ${ }^{2}$ University of Texas Southwestern Medical Center, Dallas, Texas; ${ }^{3}$ University of Washington, Seattle, Washington, USA

Correspondence: Dr Elizabeth D Ferucci, Alaska Native Tribal Health Consortium, 4315 Diplomacy Drive, Anchorage, Alaska 99508, USA.

Telephone 907-729-1560, fax 907-729-1570, e-mail edferucci@anthc.org

Received for publication June 23, 2010. Accepted July 29, 2010 
HPRT is responsible for the production of the active metabolite 6-thioguanine nucleotides (6-TGN), which account for the therapeutic effects of azathioprine but have been associated with bone marrow toxicity at high levels. TPMT generates inactive metabolites of 6-MP. The gene encoding the TPMT enzyme is highly polymorphic, thus, leading to varying levels of enzyme activity in individuals. Approximately $89 \%$ of the Caucasian population has normal TPMT activity, 11\% has intermediate activity and $0.3 \%$ has undetectable activity (5). TPMT genotype testing has been used to predict TPMT enzyme activity, and the presence or absence of mutations in TPMT alleles has correlated well with TPMT enzyme activity (6).

The American Association for the Study of Liver Diseases guidelines for $\mathrm{AIH}$ recommend consideration of pretreatment testing for TPMT activity in all patients (2). It has been recommended that individuals with intermediate TPMT activity or a heterozygous genotype receive lower doses of azathioprine and be monitored more carefully than those with normal TPMT activity or a wild-type genotype, and that those with absent TPMT activity or with homozygous mutations receive azathioprine with great caution or not at all (4). Although individuals with inflammatory bowel disease (IBD) and abnormal TPMT activity are more likely to develop toxicity from azathioprine, it has been demonstrated that the majority of individuals with IBD who experience adverse reactions to azathioprine have a normal TPMT genotype or phenotype $(7,8)$. Therefore, the utility of routine TPMT testing in either IBD or AIH remains unclear.

In IBD, levels of 6-TGN metabolites have been demonstrated to correlate with remission, and a recent meta-analysis (9) confirmed this association. However, there is significant heterogeneity between individual studies and patients. The meta-analysis (9) reported that $62 \%$ of patients above the threshold value for 6 -TGN (ranging from $230 \mathrm{pmol} / 8 \times 10^{8}$ to $260 \mathrm{pmol} / 8 \times 10^{8}$ red blood cells [RBCs]) were in remission versus $36 \%$ of patients who were below the threshold, thus demonstrating considerable overlap. In IBD, leukopenia has been associated with higher 6-TGN levels, while hepatotoxicity has been associated with elevated levels of the inactive metabolite of azathioprine 6-methylmercaptopurine (6-MMP) (10). In AIH, studies have not determined a target range for 6-TGN levels. Several studies in predominantly Caucasian populations (11-13) have found limited utility in monitoring levels of 6-TGN and 6-MMP metabolites during azathioprine therapy.

In the present study of $\mathrm{AIH}$, which included a populationbased cohort of Alaska Native people, who have a high prevalence of AIH (14) and a university clinic-based non-Caucasian cohort, we evaluated the following: the prevalence of TPMT genotypic mutations in non-Caucasian patients with $\mathrm{AIH}$; the association between TPMT genotype and enzyme activity; the impact of TPMT enzyme activity on levels of the azathioprine metabolites 6-TGN and 6-MMP; and the association between 6-TGN and 6-MMP levels and remission or leukopenia in AIH patients treated with azathioprine.

\section{METHODS}

Inclusion criteria

Individuals were included if they met the criteria for definite or probable AIH based on the revised criteria from the International Autoimmune Hepatitis Group published in 1999 (15). The
1999 criteria were used rather than the simplified 2008 criteria $(16,17)$ because they were designed for classification of AIH for research purposes rather than clinical care. A probable diagnosis of $\mathrm{AIH}$ is based on a cumulative score of greater than 15 and a definite diagnosis if the cumulative score is greater than 17 before treatment. All participants provided informed consent to participate in the study. Study participants were recruited at the Alaska Native Medical Center (ANMC, Alaska, USA) and the University of Texas Southwestern Medical Center (UTSW, Texas, USA). The study was approved by the Alaska Area institutional review board, the institutional review board at UTSW and the Alaska Native Tribal Health Consortium and Southcentral Foundation Boards of Directors. All individuals with an identified TPMT genotype and phenotype were included, regardless of whether they received azathioprine. For the analysis of the association between TPMT genotype and TPMT enzyme activity, only individuals with data from both parameters were included. For the analysis of azathioprine metabolites and response to therapy, only participants treated with azathioprine and with at least one measurement of metabolites while taking azathioprine were included. Because an insufficient number of individuals had multiple metabolite measurements to analyze the data longitudinally, a cross-sectional analysis with outcome variables defined at the time of the metabolite measurement was performed. In the case of multiple results, the most recent result was used. The dose of azathioprine was recorded in $\mathrm{mg} / \mathrm{kg} /$ day using the daily dose of azathioprine and the recorded weight in the medical record closest to the time of metabolite draw.

\section{TPMT and azathioprine metabolites}

Testing for TPMT genotype and phenotype, 6-TGN and 6-MMP were performed on whole blood at Prometheus Laboratories (USA) using the proprietary PRO-Predict TPMT Genetic Assessment assay. These tests determine a patient's potential and actual ability to produce TPMT using an allelic discrimination polymerase chain reaction methodology to detect the presence or absence of three polymorphisms in the TPMT gene, which is located on chromosome 6. These TPMT polymorphisms have been demonstrated to correlate well with phenotype in a Caucasian population (6). Individuals were categorized as having a wild-type heterozygous mutation or homozygous mutation of TPMT. TPMT enzyme activity was classified as low (less than 6.7 enzyme units [EU]/mL), intermediate $(6.7 \mathrm{EU} / \mathrm{mL}$ to $23.6 \mathrm{EU} / \mathrm{mL}$ ) or high (greater than 23.6 EU/mL). Measurement of azathioprine metabolites uses high performance liquid chromatography and results are reported in $\mathrm{pmol} / 8 \times 10^{8} \mathrm{RBCs}$.

\section{Definition of remission}

At the time of azathioprine metabolite measurement, individuals were classified as being in remission or not. Remission of AIH was defined as an alanine aminotransferase (ALT) level of less than 1.5 times the upper limit of normal (40 U/L) and no clinical signs of active liver disease.

\section{Definition of leukopenia}

Based on the definition used in other studies of AIH $(10,18)$, leukopenia was defined as a white blood cell (WBC) count of less than $4 \times 10^{9} / \mathrm{L}$ on a blood draw within one month of the metabolite draw. Other side effects such as nausea, vomiting 
TABLE 1

Characteristics of the study population

\begin{tabular}{lcc}
\hline & $\begin{array}{c}\text { Alaska Native } \\
\text { Medical Center* } \\
(\mathbf{n}=57)\end{array}$ & $\begin{array}{c}\text { University of Texas } \\
\text { Southwestern } \\
(\mathbf{n}=\mathbf{1 4})\end{array}$ \\
\hline Age $^{\ddagger}$, years, mean $\pm \mathrm{SD}$ & $52.2 \pm 14.7$ & $45.0 \pm 15.4$ \\
Female sex, $\mathrm{n}(\%)$ & $53(93.0)$ & $13(92.9)$ \\
Race/ethnicity & & \\
$\quad$ Alaska Native/American Indian & $57(100)$ & $0(0)$ \\
African-American & & $7(46.7)$ \\
Hispanic & & $7(46.7)$ \\
TPMT genotype & & \\
Wildtype & $46(80.7)$ & $13(92.9)$ \\
Heterozygous 1/*3A & $11(19.3)$ & $1(6.7)$ \\
Homozygous mutant & $0(0)$ & $0(0)$ \\
TPMT enzyme activity ${ }^{\S}$ & $\mathrm{n}=56$ & $\mathrm{n}=14$ \\
Normal & $42(75)$ & $13(92.9)$ \\
Intermediate & $14(25)$ & $1(6.7)$ \\
Low & $0(0)$ & $0(0)$ \\
\hline
\end{tabular}

Data presented as $n$ (\%) unless otherwise indicated. *Anchorage, Alaska, USA; 'Dallas, Texas, USA; ${ }^{\ddagger}$ Age at September 15, 2005; ${ }^{\S}$ Thiopurine methyltransferase (TPMT) enzyme activity: normal greater than 23.6 enzyme units $(E U) / m L$, intermediate $6.7 \mathrm{EU} / \mathrm{mL}$ to $23.6 \mathrm{EU} / \mathrm{mL}$, low less than $6.7 \mathrm{EU} / \mathrm{mL}$

and/or rash, or bone marrow toxicity or pancreatitis leading to discontinuation of azathioprine were documented but not considered to be the primary outcome measure in the present analysis.

\section{Statistical analysis}

Fisher's exact test was used for comparisons of proportions. Correlations were tested using Spearman's correlation coefficient. Comparisons of means were performed using the nonparametric Wilcoxon two-sample test. A two-tailed $\mathrm{P}<0.05$ was considered to be statistically significant.

\section{Study population}

\section{RESULTS}

The present study recruited 71 participants. The characteristics of the study population are summarized in Table 1. Of the 57 individuals recruited at ANMC, 56 had TPMT genotyping and phenotyping performed, while all 14 individuals recruited at UTSW had TPMT genotyping and phenotyping performed. Forty-nine individuals had metabolite levels drawn at least once while taking azathioprine, 48 of whom had both metabolite levels measured and TPMT phenotyping performed. Six of the 57 patients from ANMC met the criteria for probable $\mathrm{AIH}$, and 51 of 57 met the criteria for definite $\mathrm{AIH}$.

\section{Correlation of TPMT genotype and phenotype}

The distribution of TPMT genotypes is summarized in Table 1 . There was no significant difference in the frequency of heterozygous mutations between ANMC and UTSW participants $(\mathrm{P}=0.44$ [Fisher's exact test]). Figure 1 illustrates the relationship between TPMT genotype and TPMT enzyme activity. Individuals with the wild-type genotype had higher TPMT enzyme activity levels, although three individuals with the wild-type genotype had intermediate levels of enzyme activity. Individuals with heterozygous mutations in TPMT (all were 1/*3A mutations) had lower levels of TPMT enzyme activity, and only one of the heterozygotes had normal enzyme activity. The association between genotype

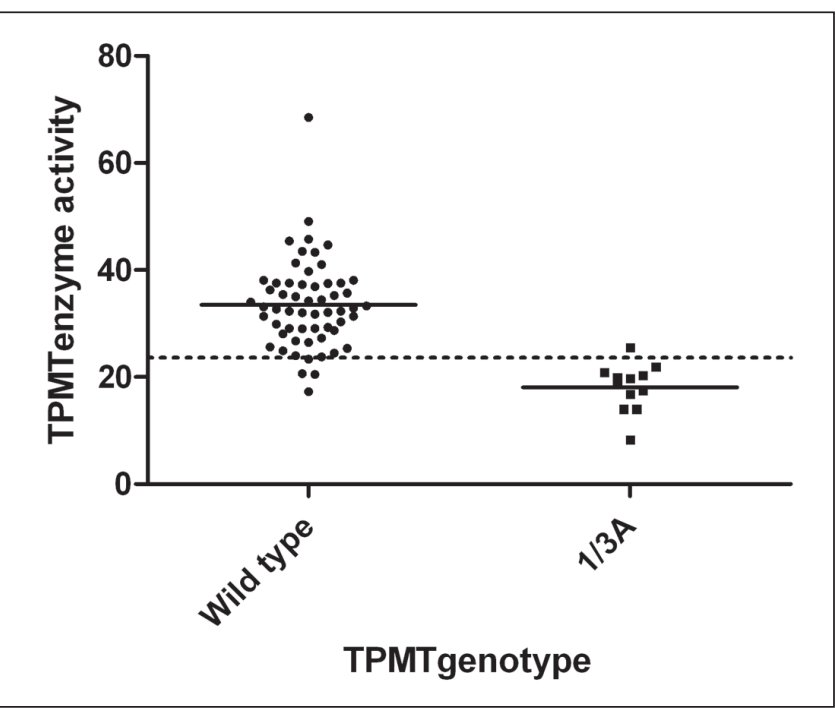

Figure 1) Thiopurine methyltransferase (TPMT) enzyme activity according to genotype. 1/3A Heterozygous TPMT*3A mutation; Dashed line at 23.6 enzyme units/mL marks the cut-off between intermediate and high TPMT enzyme activity

and category of enzyme activity (normal versus intermediate) was highly significant $(\mathrm{P}<0.0001$ [Fisher's exact test]).

Association between azathioprine dose and metabolite levels The association between azathioprine dose (in $\mathrm{mg} / \mathrm{kg} / \mathrm{day}$ ) and 6-TGN and 6-MMP metabolite levels was evaluated. Plots were stratified according to TPMT enzyme activity category (normal versus intermediate) because it was apparent that the dose and response varied. As illustrated in Figure 2, the levels of 6-TGN metabolites increased with azathioprine dose in the setting of normal TPMT phenotype (Spearman's $\mathrm{r}=0.41 ; \mathrm{P}=0.01$ ). However, in the setting of intermediate TPMT enzyme activity, there was no relationship between azathioprine dose and 6-TGN levels (Spearman's $r=0.24 ; \mathrm{P}=0.48$ ). Figure 3 illustrates a similar phenomenon for 6-MMP levels, which only correlated with azathioprine dose in individuals with a normal TPMT phenotype (Spearman's $r=0.71 ; P=<0.0001$ ), but not in individuals with an intermediate TPMT phenotype (Spearman's $\mathrm{r}=0.21 ; \mathrm{P}=0.54$ ).

\section{Association between azathioprine metabolites, TPMT phenotype and remission}

Of 49 individuals who underwent measurement of metabolite levels while on azathioprine, 41 were in remission at the time of the blood draw. As shown in Table 2, the mean azathioprine dose was similar in patients who were in remission compared with those who were not in remission and, in both cases, the mean dose was approximately $1 \mathrm{mg} / \mathrm{kg} / \mathrm{day}$. There was no statistically significant difference in TPMT enzyme activity category, mean level of 6-TGN, 6-TGN level adjusted for azathioprine dose, or the proportion of individuals with 6-TGN levels of more than $230 \mathrm{pmol} / 8 \times 10^{8}$ RBCs. Notably, the mean level of 6-TGN was lower in those in remission than not in remission, and only $14.6 \%$ of those in remission had 6-TGN levels above $230 \mathrm{pmol} / 8 \times 10^{8} \mathrm{RBCs}$, compared with $25 \%$ of individuals not in remission. There was also no difference in 6-MMP levels according to remission status, and no patients had a 6-MMP level of greater than $5700 \mathrm{pmol} / 8 \times 10^{8} \mathrm{RBCs}$. 

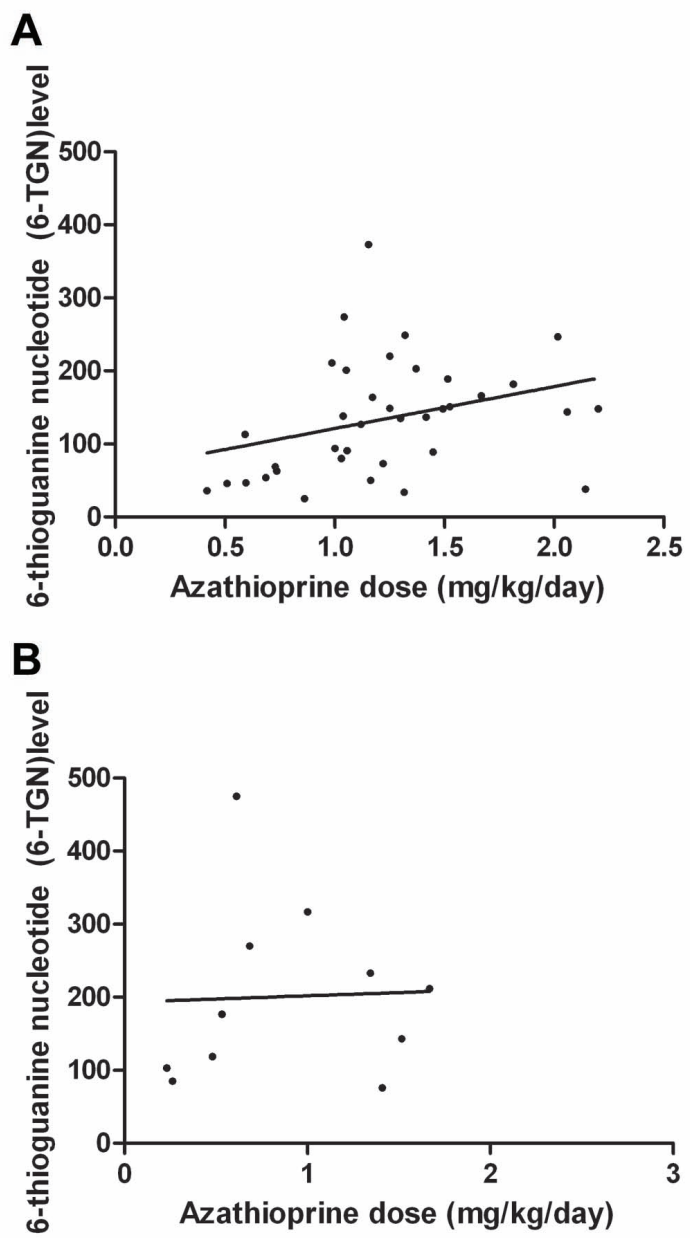

Figure 2) 6-thioguanine nucleotide levels (pmol/8 $\times 10^{8} \mathrm{red}$ blood cells) versus azathioprine dose stratified according to thiopurine methyltransferase (TPMT) enzyme activity (normal versus intermediate). A Normal TPMT enzyme activity. B Intermediate TPMT enzyme activity

\section{Association among azathioprine metabolites, TPMT} phenotype and leukopenia

Forty-eight individuals were classified based on the presence or absence of leukopenia (Table 3). One individual with systemic lupus erythematosus (SLE) was excluded from this particular analysis because the etiology of the leukopenia was believed to be probably due to SLE. A total of nine individuals with leukopenia presumably due to azathioprine were identified. There was no statistically significant difference in azathioprine dose, TPMT enzyme activity, 6-TGN or 6-MMP levels in individuals with leukopenia than in those without. Although the most common toxicity related to azathioprine was leukopenia, as included in the analysis, or other bone marrow toxicity: one patient each had pancreatitis, oral ulcers and headaches that led to discontinuation of azathioprine. Collectively considering all of the toxicities did not alter the results of the analysis.

\section{DISCUSSION}

In the first study of the management of AIH in predominantly non-Caucasian populations (5), we found the distribution of TPMT genotypes to be similar to that reported in studies of

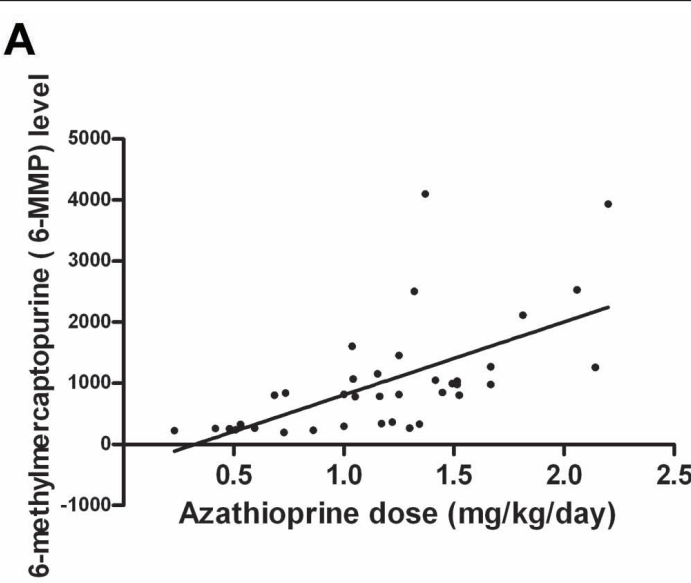

B

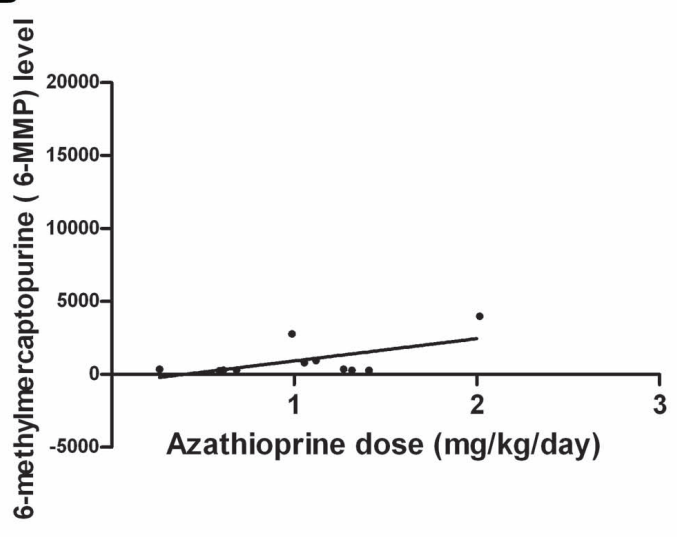

Figure 3) 6-methylmercaptopurine levels (pmol/8 $\times 10^{8} \mathrm{red}$ blood cells) versus azathioprine dose stratified according to thiopurine methyltransferase (TPMT) enzyme activity (normal versus intermediate). A Normal TPMT enzyme activity. B Intermediate TPMT enzyme activity

Caucasian blood donors. We demonstrated that, while TPMT genotype and phenotype correlated well, individuals with leukopenia due to azathioprine were no more likely to have intermediate TPMT enzyme activity than those without leukopenia. We found that most individuals taking azathioprine for AIH were maintained in remission at a dose of slightly more than $1 \mathrm{mg} / \mathrm{kg} /$ day. This dose is considerably lower than the $2.5 \mathrm{mg} / \mathrm{kg}$ of azathioprine that correlates with remission in IBD (19). No level of 6-TGN metabolites was predictably associated with remission or leukopenia. Finally, the level of 6-TGN and 6-MMP metabolites only correlated with the azathioprine dose in individuals with normal TPMT enzyme activity. In persons found to have an intermediate level of TPMT enzyme activity, these metabolites were not correlated with azathioprine dose.

Three previous studies (11-13) evaluated TPMT genotype and enzyme activity in mostly Caucasian AIH patients and, in all three, TPMT genotype and phenotype correlated well, but not perfectly. One study of $72 \mathrm{AIH}$ patients (11) found that TPMT enzyme activity did not invariably predict response to azathioprine. However, TPMT enzyme activity was lowest in patients who did not tolerate azathioprine, intermediate in patients in remission on azathioprine alone, and highest in patients who required corticosteroids in addition to azathioprine to attain remission. The second study of $86 \mathrm{AIH}$ 
TABLE 2

Azathioprine dose and metabolite levels of patients in remission versus those not in remission

\begin{tabular}{|c|c|c|c|}
\hline & \multicolumn{2}{|c|}{ Remission } & \multirow[b]{2}{*}{$\mathbf{P}$} \\
\hline & Yes $(n=41)$ & No $(n=8)$ & \\
\hline \multicolumn{4}{|l|}{ Azathioprine dose, mg/kg/day } \\
\hline Mean \pm SD & $1.16 \pm 0.48$ & $1.09 \pm 0.50$ & $0.90 *$ \\
\hline Median & 1.16 & 1.16 & \\
\hline $\begin{array}{l}\text { Intermediate TPMT enzyme activity }{ }^{\dagger} \text {, } \\
\text { n (\%) }\end{array}$ & $8(19.5)$ & $\begin{array}{c}2(28.6) \\
(n=7)\end{array}$ & $0.63^{\star *}$ \\
\hline \multicolumn{4}{|l|}{6 -TGN, pmol/ $8 \times 10^{8}$ RBCs } \\
\hline Mean \pm SD & $143 \pm 79$ & $189 \pm 144$ & $0.43^{\star}$ \\
\hline Median & 138 & 189 & \\
\hline \multicolumn{4}{|c|}{6 -TGN adjusted for azathioprine dose, pmol/ $8 \times 10^{8} \mathrm{RBCs}$} \\
\hline Mean \pm SD & $146 \pm 103$ & $207 \pm 238$ & $0.76^{*}$ \\
\hline Median & 104 & 113 & \\
\hline $\begin{array}{l}\text { 6-TGN above } 230 \mathrm{pmol} / 8 \times 10^{8} \mathrm{RBCs} \text {, } \\
\mathrm{n}(\%)\end{array}$ & $6(14.6)$ & $2(25)$ & $0.60^{* *}$ \\
\hline \multicolumn{4}{|l|}{ 6-MMP, pmol/ $8 \times 10^{8} \mathrm{RBCs}$} \\
\hline Mean \pm SD & $1066 \pm 1071$ & $672 \pm 416$ & $0.82^{\star}$ \\
\hline Median & 806 & 606.5 & \\
\hline \multicolumn{4}{|c|}{ 6-MMP adjusted for azathioprine dose, pmol/8 $\times 10^{8} \mathrm{RBCs}$} \\
\hline Mean \pm SD & $870 \pm 666$ & $604 \pm 222$ & $0.42^{\star}$ \\
\hline Median & 679 & 589 & \\
\hline
\end{tabular}

*Wilcoxon 2-sample test; ${ }^{\dagger}$ Data regarding thiopurine methyltransferase (TPMT) enzyme activity level available for 48 of 49 patients; ${ }^{* \star} F$ Fisher's exact test. 6-MMP 6-methylmercaptopurine; 6-TGN 6-thioguanine nucleotides; RBCs Red blood cells

patients (12) found that TPMT genotype and/or phenotype did not predict toxicity of azathioprine and were no different in patients requiring corticosteroids to attain remission compared with azathioprine alone. The most recent study (13) found no difference in azathioprine dose or adverse event rates between individuals with normal compared with intermediate TPMT enzyme activity. Our study confirms the findings that TPMT genotype and phenotype correlate well (6,11-13). Furthermore, our findings that TPMT phenotype is not associated with remission or toxicity are consistent with these three studies of AIH. Supporting these findings, studies of other autoimmune diseases, including SLE and antineutrophil cytoplasmic antibody-associated vasculitis $(20,21)$, have also found that TPMT genotype and/or phenotype do not predict adverse events including myelosuppression.

In AIH, two studies $(12,13)$ reported a correlation between azathioprine dose and 6-TGN and 6-MMP levels. Studies in IBD have been inconsistent, and several studies have demonstrated that the dose of azathioprine and levels of its metabolites do not correlate well $(18,22,23)$. However, no study in IBD or AIH has stratified the impact of azathioprine dose on levels of metabolites according to TPMT phenotype. Our data demonstrated that azathioprine dose correlates with metabolite levels only in individuals with normal TPMT enzyme activity. Based on the mechanism of metabolism of azathioprine, one might have expected higher levels of azathioprine metabolites in individuals with intermediate enzyme activity. This lack of correlation between azathioprine dose and metabolite levels in individuals with intermediate TPMT enzyme activity should be investigated in other populations.
TABLE 3

Azathioprine dose and metabolite levels of patients with leukopenia versus no leukopenia

\begin{tabular}{|c|c|c|c|}
\hline & \multicolumn{2}{|c|}{ Leukopenia* } & \multirow[b]{2}{*}{$\mathbf{P}$} \\
\hline & Yes $(n=9)$ & No $(n=39)$ & \\
\hline \multicolumn{4}{|l|}{ Azathioprine dose, mg/kg/day } \\
\hline Mean $\pm \mathrm{SD}$ & $1.06 \pm 0.53$ & $1.18 \pm 0.47$ & $0.61^{\dagger}$ \\
\hline Median & 1.16 & 1.22 & \\
\hline $\begin{array}{l}\text { Intermediate TPMT enzyme } \\
\text { activity, n (\%) }\end{array}$ & $2(22.2)$ & $\begin{array}{l}9(23.7) \\
(n=38)\end{array}$ & $1.00^{\ddagger}$ \\
\hline \multicolumn{4}{|l|}{$6-\mathrm{TGN}, \mathrm{pmol} / 8 \times 10^{8} \mathrm{RBCs}$} \\
\hline Mean \pm SD & $103 \pm 67$ & $163 \pm 137$ & $0.09^{\dagger}$ \\
\hline Median & 91 & 114 & \\
\hline \multicolumn{4}{|c|}{6 -TGN adjusted for azathioprine dose, $\mathrm{pmol} / 8 \times 10^{8} \mathrm{RBCs}$} \\
\hline Mean $\pm \mathrm{SD}$ & $126 \pm 125$ & $162 \pm 137$ & \\
\hline Median & 90 & 114 & $0.30^{\dagger}$ \\
\hline $\begin{array}{l}\text { 6-TGN above } 230 \mathrm{pmol} / 8 \times 10^{8} \\
\text { RBCs, } \mathrm{n}(\%)\end{array}$ & $0(0)$ & $8(21)$ & $0.32^{\ddagger}$ \\
\hline \multicolumn{4}{|l|}{ 6-MMP, pmol/ $8 \times 10^{8} \mathrm{RBCs}$} \\
\hline Mean \pm SD & $671 \pm 614$ & $1097 \pm 1066$ & $0.13^{\dagger}$ \\
\hline Median & 343 & 823 & \\
\hline \multicolumn{4}{|c|}{ 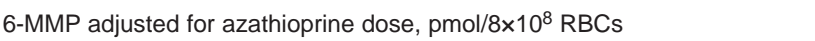 } \\
\hline Mean $\pm \mathrm{SD}$ & $622 \pm 313$ & $884 \pm 671$ & $0.41^{\dagger}$ \\
\hline Median & 590 & 669 & \\
\hline
\end{tabular}

* Leukopenia defined as a white blood cell count of less than $4 \times 10^{9} / \mathrm{L}$ on blood draw within one month of metabolite draw. One patient was excluded because their pancytopenia was believed to be due to systemic lupus erythematosus; ${ }^{\dagger}$ Wilcoxon 2-sample test; ${ }^{\ddagger}$ Fisher's exact test. 6-MMP 6-methylmercaptopurine; 6-TGN 6-thioguanine nucleotides; RBCs Red blood cells; TPMT Thiopurine methyltransferase

Studies of IBD have identified cut-offs for 6-TGN (above a threshold value ranging from $230 \mathrm{pmol} / 8 \times 10^{8}$ to $260 \mathrm{pmol} / 8 \times 10^{8}$ RBCs) that are associated with remission (9). No previous study in adults with AIH has validated the cut-offs recommended in IBD, although a study of pediatric patients with AIH showed that in eight patients with low levels of 6-TGN, dose escalation of azathioprine to achieve target 6-TGN levels between $235 \mathrm{pmol} / 8 \times 10^{8}$ and $450 \mathrm{pmol} / 8 \times 10^{8} \mathrm{RBCs}$ was safe and reduced ALT levels and steroid requirements (24). In adults with $\mathrm{AIH}$, one study (12) demonstrated that the mean level of 6-TGN in patients in remission was $152 \mathrm{pmol} / 8 \times 10^{8}$ RBCs in patients without prednisone (with mean azathioprine dose of $1.52 \mathrm{mg} / \mathrm{kg} / \mathrm{day})$ and $157 \mathrm{pmol} / 8 \times 10^{8} \mathrm{RBCs}$ in patients on azathioprine and prednisone (mean azathioprine dose $1.71 \mathrm{mg} / \mathrm{kg} /$ day). Another study (11) found higher mean 6-TGN levels ( $\left.264 \mathrm{pmol} / 8 \times 10^{8} \mathrm{RBCs}\right)$ with a similar mean dose of azathioprine $(1.3 \mathrm{mg} / \mathrm{kg} /$ day $)$. Hindorf et al (13) recently demonstrated that 6-TGN levels were similar in patients with complete remission and partial remission and, in both cases, were low $\left(113 \mathrm{pmol} / 8 \times 10^{8}\right.$ and $121 \mathrm{pmol} / 8 \times 10^{8}$ RBCs, respectively) compared with levels described in remission in IBD. In the present study, we demonstrated that the mean dose-adjusted 6-TGN level in remission was $146 \mathrm{pmol} / 8 \times 10^{8}$ RBCs, also significantly lower than the cut-offs used in IBD, and not statistically different from individuals who were not in remission. Most studies in IBD have also suggested that higher levels of 6 -TGN (generally above $400 \mathrm{pmol} / 8 \times 10^{8}$ to $450 \mathrm{pmol} / 8 \times 10^{8} \mathrm{RBCs}$ ) are associated with leukopenia (10), but not all studies have shown that association (25). These higher levels of 6-TGN were usually seen with doses of 
azathioprine of approximately $2.5 \mathrm{mg} / \mathrm{kg} /$ day (19). We did not find any association between 6-TGN levels and leukopenia in AIH. Furthermore, remission was achieved at much lower doses of azathioprine than occurred with remission in IBD, with leukopenia observed at dramatically lower levels of 6-TGN. Other mechanisms may exist in persons with $\mathrm{AIH}$ that, when combined with small doses of azathioprine, contribute to bone marrow toxicity such as autoantibodies to marrow cells.

The present study has some limitations. First, the small sample size may not have enabled us to detect some associations. However, AIH is a rare disease and few studies have significant sample sizes primarily because very few centres in the world follow a large number of these patients. In addition, we reported data in predominantly non-Caucasian AIH patients, which have not been described in most of the literature on AIH. A second limitation is the possibility that we missed rare mutations in the TPMT gene, given that we were only testing for the three most common mutations, as is standard practice using commercially available tests. Although these common alleles account for the vast majority of TPMT mutations in all populations studied to date, it is possible that we missed a novel mutant allele such as TPMT*6, an allele described in the Korean population (26). However, we used TPMT phenotype for the remainder of the analyses, which is not affected by this limitation, and we demonstrated that genotype and phenotype correlated well.

The information from the present study has clinical applications. First, it demonstrated that a normal TPMT enzyme activity does not preclude azathioprine toxicity. However, we believe that TPMT phenotype testing before initiation of azathioprine to identify individuals with very low enzyme activity is still warranted. Second, our study confirmed that there is

\section{REFERENCES}

1. Krawitt EL. Autoimmune hepatitis. N Engl J Med 2006;354:54-66.

2. Czaja AJ, Freese DK. Diagnosis and treatment of autoimmune hepatitis. Hepatology 2002;36:479-97.

3. Johnson PJ, McFarlane IG, Williams R. Azathioprine for long-term maintenance of remission in autoimmune hepatitis. N Engl J Med 1995;333:958-63.

4. Heneghan MA, McFarlane IG. Current and novel immunosuppressive therapy for autoimmune hepatitis. Hepatology 2002;35:7-13.

5. Weinshilboum RM, Sladek SL. Mercaptopurine pharmacogenetics: Monogenic inheritance of erythrocyte thiopurine methyltransferase activity. Am J Hum Genet 1980;32:651-62.

6. Yates CR, Krynetski EY, Loennechen T, et al. Molecular diagnosis of thiopurine S-methyltransferase deficiency: Genetic basis for azathioprine and mercaptopurine intolerance. Ann Intern Med 1997;126:608-14.

7. Colombel JF, Ferrari N, Debuysere H, et al. Genotypic analysis of thiopurine S-methyltransferase in patients with Crohn's disease and severe myelosuppression during azathioprine therapy. Gastroenterology 2000;118:1025-30.

8. Gearry RB, Barclay ML, Burt MJ, et al. Thiopurine S-methyltransferase (TPMT) genotype does not predict adverse drug reactions to thiopurine drugs in patients with inflammatory bowel disease. Aliment Pharmacol Ther 2003;18:395-400.

9. Osterman MT, Kundu R, Lichtenstein GR, Lewis JD. Association of 6-thioguanine nucleotide levels and inflammatory bowel disease activity: A meta-analysis. Gastroenterology 2006;130:1047-53.

10. Dubinsky MC, Lamothe S, Yang HY, et al. Pharmacogenomics and metabolite measurement for 6-mercaptopurine therapy in inflammatory bowel disease. Gastroenterology 2000;118:705-13.

11. Langley PG, Underhill J, Tredger JM, Norris S, McFarlane IG. Thiopurine methyltransferase phenotype and genotype in relation limited utility to monitoring levels of 6-TGN and 6-MMP in individuals of any ethnicity with AIH who are maintained on azathioprine. Given the limitations of these tests, we would not recommend clinicians to use these parameters to routinely follow their patients on azathioprine. The mainstay of testing for patients on azathioprine should still be the complete blood count with differential and ALT levels. Finally, it appears that remission can be maintained in most individuals on azathioprine at much lower doses - approximately $1 \mathrm{mg} / \mathrm{kg}$ than are necessary in IBD.

\section{SUMMARY}

We performed a comprehensive study of non-Caucasian individuals with AIH to examine data regarding TPMT genotype and phenotype, azathioprine metabolites, and their association with remission of $\mathrm{AIH}$ or leukopenia due to azathioprine. The data from the present and other studies in $\mathrm{AIH}$ provide a strong rationale against the use of measuring 6-TGN and 6-MMP levels in the routine management of AIH patients on azathioprine. Additional studies would be useful to determine whether other markers could be helpful in predicting $\mathrm{AIH}$ remission and azathioprine toxicity. Future studies should include sufficient representation from different racial and ethnic groups to determine whether the findings are generalizable to other populations.

GRANT SUPPORT: This study was funded by a Native American Research Centers for Health grant (NARCH, NIAID/IHS U26IHS 300012).

DISCLOSURE: The authors have no financial disclosures or conflicts of interest to declare. to azathioprine therapy in autoimmune hepatitis. J Hepatol 2002;37:441-7.

12. Heneghan MA, Allan ML, Bornstein JD, Muir AJ, Tendler DA. Utility of thiopurine methyltransferase genotyping and phenotyping, and measurement of azathioprine metabolites in the management of patients with autoimmune hepatitis. J Hepatol 2006;45:584-91.

13. Hindorf $U$, Jahed K, Bergquist A, et al. Characterisation and utility of thiopurine methyltransferase and thiopurine metabolite measurements in autoimmune hepatitis. J Hepatol 2009;52:106-11.

14. Hurlburt KJ, McMahon BJ, Deubner H, Hsu-Trawinski B, Williams JL, Kowdley KV. Prevalence of autoimmune liver disease in Alaska Natives. Am J Gastroenterol 2002;97:2402-7.

15. Alvarez F, Berg PA, Bianchi FB, et al. International Autoimmune Hepatitis Group Report: Review of criteria for diagnosis of autoimmune hepatitis. J Hepatol 1999;31:929-38.

16. Hennes EM, Zeniya M, Czaja AJ, et al. Simplified criteria for the diagnosis of autoimmune hepatitis. Hepatology 2008;48:169-76.

17. Luxon BA. Diagnosis and treatment of autoimmune hepatitis. Gastroenterol Clin North Am 2008;37:461-78.

18. Achkar JP, Stevens T, Easley K, Brzezinski A, Seidner D, Lashner B. Indicators of clinical response to treatment with six-mercaptopurine or azathioprine in patients with inflammatory bowel disease. Inflamm Bowel Dis 2004;10:339-45.

19. Prefontaine E, Sutherland LR, Macdonald JK, Cepoiu M. Azathioprine or 6-mercaptopurine for maintenance of remission in Crohn's disease. Cochrane Database Syst Rev 2009:CD000067.

20. Naughton MA, Battaglia E, O'Brien S, Walport MJ, Botto M. Identification of thiopurine methyltransferase (TPMT) polymorphisms cannot predict myelosuppression in systemic lupus erythematosus patients taking azathioprine. Rheumatology (Oxford) 1999;38:640-4. 
21. Stassen PM, Derks RP, Kallenberg CG, Stegeman CA. Thiopurinemethyltransferase (TPMT) genotype and TPMT activity in patients with anti-neutrophil cytoplasmic antibody-associated vasculitis: Relation to azathioprine maintenance treatment and adverse effects. Ann Rheum Dis 2009;68:758-9.

22. Wright S, Sanders DS, Lobo AJ, Lennard L. Clinical significance of azathioprine active metabolite concentrations in inflammatory bowel disease. Gut 2004;53:1123-8.

23. Hindorf U, Lyrenas E, Nilsson A, Schmiegelow K. Monitoring of long-term thiopurine therapy among adults with inflammatory bowel disease. Scand J Gastroenterol 2004;39:1105-12.
24. Rumbo C, Emerick KM, Emre S, Shneider BL.

Azathioprine metabolite measurements in the treatment of autoimmune hepatitis in pediatric patients: A preliminary report. J Pediatr Gastroenterol Nutr 2002;35:391-8.

25. Goldenberg BA, Rawsthorne P, Bernstein CN. The utility of 6-thioguanine metabolite levels in managing patients with inflammatory bowel disease. Am J Gastroenterol 2004;99:1744-8.

26. Otterness D, Szumlanski C, Lennard L, et al. Human thiopurine methyltransferase pharmacogenetics: Gene sequence polymorphisms. Clin Pharmacol Ther 1997;62:60-73. 


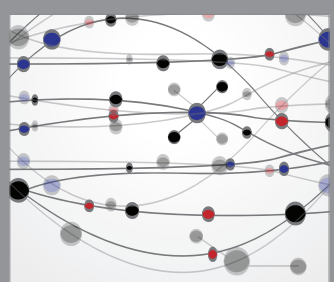

The Scientific World Journal
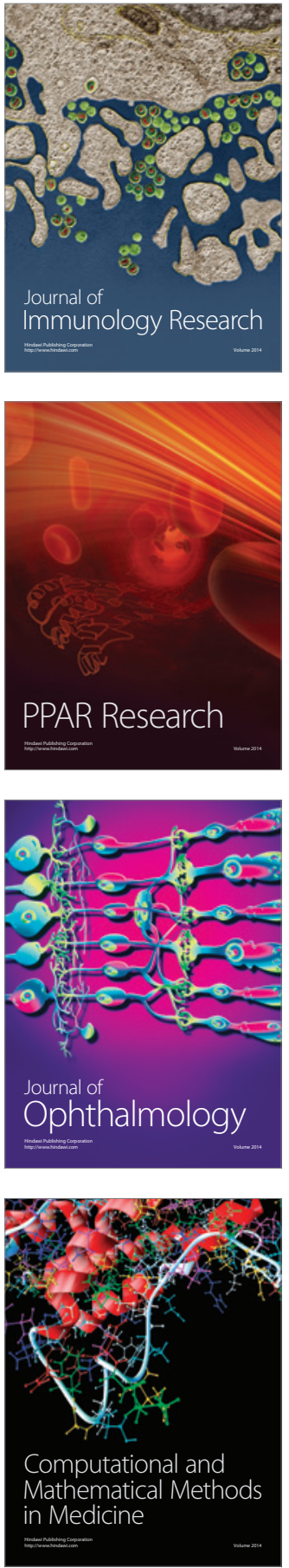

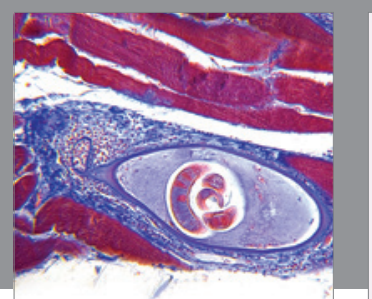

Gastroenterology Research and Practice

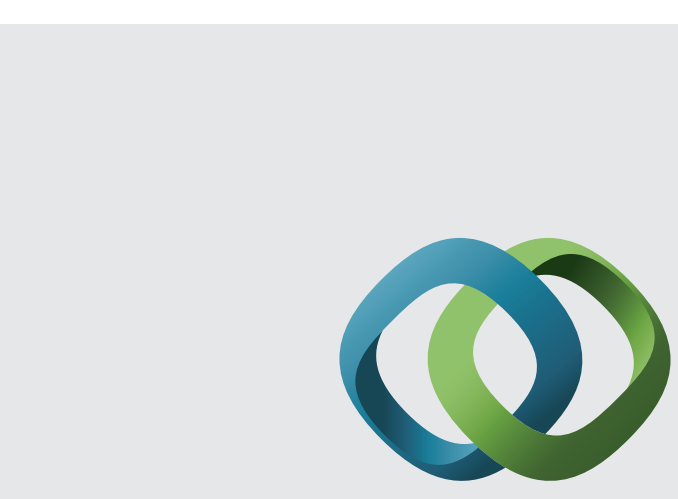

\section{Hindawi}

Submit your manuscripts at

http://www.hindawi.com
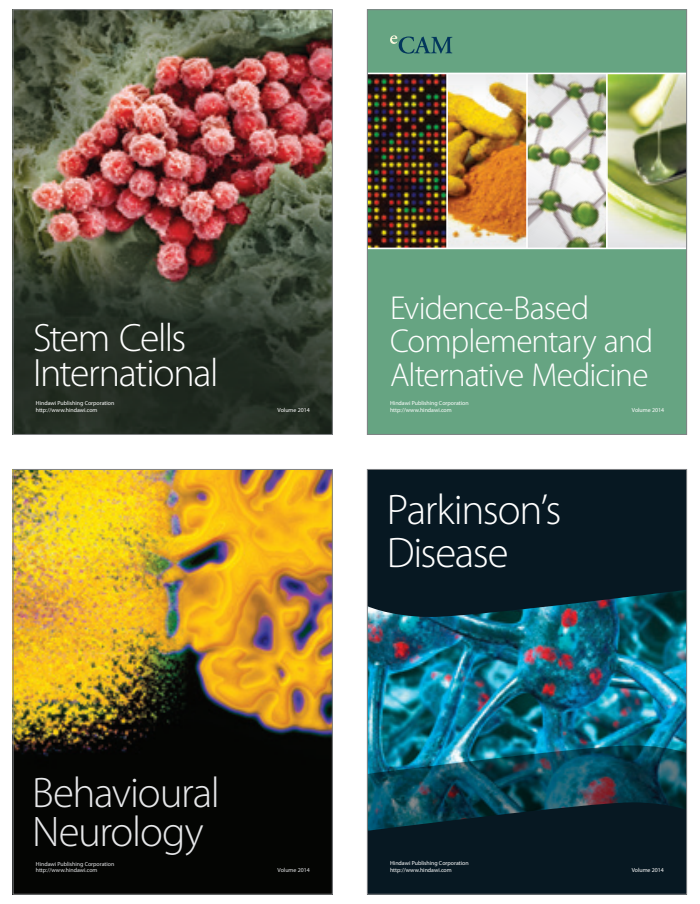
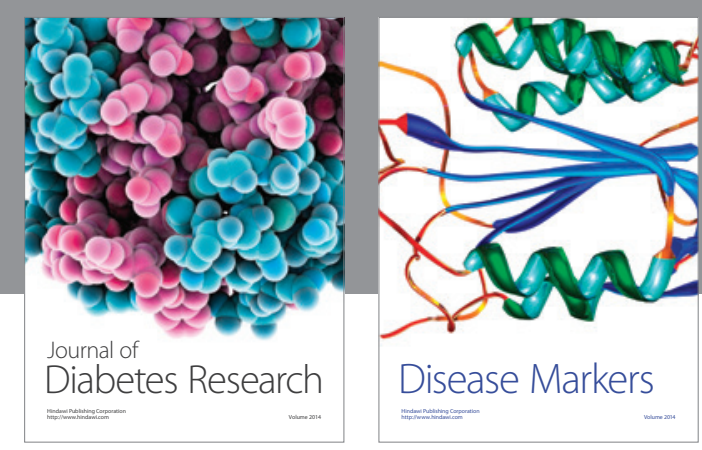

Disease Markers
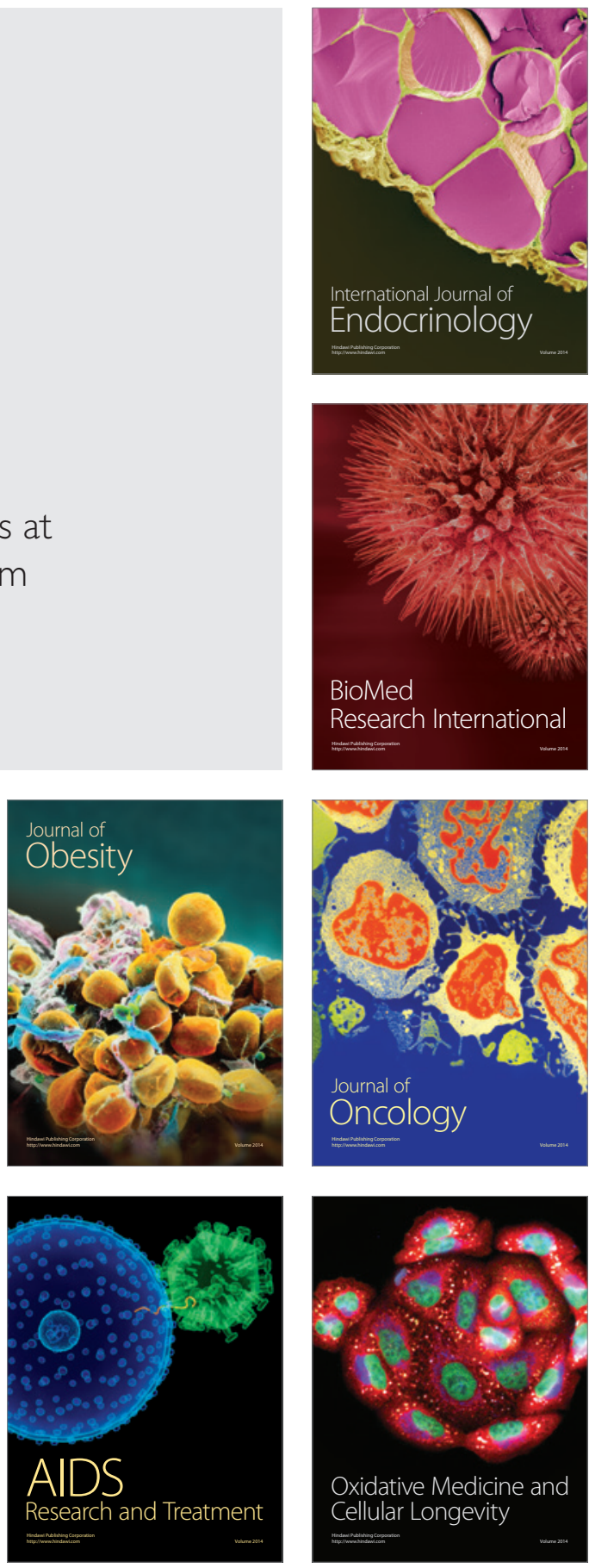